
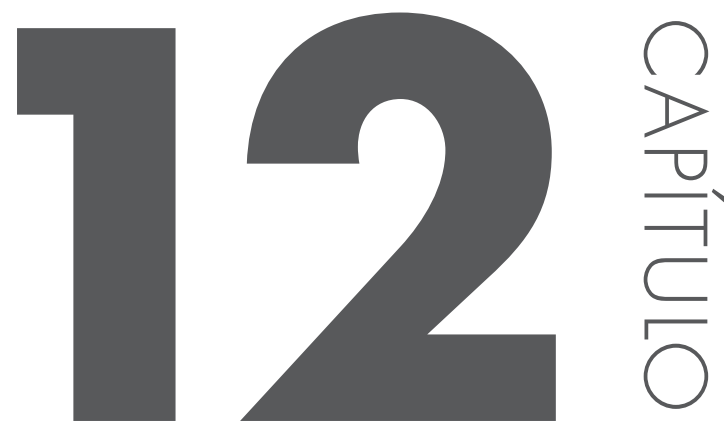

\title{
INFLUÊNCIA dA VAZÃO dE AR NO ARRASTE HIDRÁULICO EM TUBO DE HALLMOND
}

Guimarães Júnior, Paulo 1 *;

Silva, André Carlos ';

Silva, Elenice Maria Schons '

1 Universidade Federal de Goiás, Curso de Engenharia de Minas, Catalão, GO, Brasil

* email: paullo.guimaraes@hotmail.com 
Resumo: A flotação é a técnica mais utilizada na concentração de minérios de baixo teor, consistindo em uma etapa crucial para a agregação de valor ao produto. Diante disso, existem diversas variáveis que se correlacionam, sendo determinantes para o sucesso do processo de flotação, tais como a vazão de ar, intensidade de agitação, granulometria, massa específica e forma das partículas e o grau de liberação das mesmas. A partir daí, o arraste hidráulico de partículas merece destaque, o qual se faz presente no processo de flotação industrial e laboratorial, sendo fortemente influenciado pela vazão de ar, granulometria e massa específica das partículas. Em virtude da existência de poucos estudos relacionados a este tema, o presente trabalho foi realizado a fim de analisar a influência da vazão de ar no arraste hidráulico de partículas em tubo de Hallimond, utilizando partículas de apatita. Para tal, os ensaios de arraste foram realizados admitindo-se uma fração granulométrica e quatro vazões de ar, sem adição de reagentes. Após a execução de cada ensaio, prosseguiuse com o registro dos resultados, que foram obtidos mediante a pesagem das partículas que sofreram arraste e daquelas que foram afundadas. Então, um gráfico foi traçado de modo a proporcionar uma melhor visualização do comportamento das partículas em diferentes vazões de ar frente ao arraste, demonstrando um aumento no arraste das partículas com o aumento da vazão de ar.

\section{Palavras-chave: Flotação; Arraste hidráulico; Vazão de ar}




\section{Introdução}

A mineração é responsável pelo fornecimento de grande parte das matérias - primas empregadas na produção de diversos bens de consumo, contribuindo com o aumento da qualidade de vida da população. Para isso, é necessário haver a transformação do minério bruto em produto comercializável, que ocorre através de uma etapa denominada processamento mineral, a qual pode utilizar técnicas de concentração gravítica, centrífuga, magnética ou físico-química, visando à separação dos minerais de interesse dos demais que não agregam valor comercial.

A flotação é uma técnica que merece destaque, baseada nas diferenças das características físico-químicas de superfície dos minerais para promover a separação, 
a qual é realizada numa suspensão em água (polpa), onde as partículas são obrigadas a percorrer um trajeto e num dado instante aquelas que se deseja flotar são levadas a abandoná-lo, tomando uma direção ascendente.

A diferenciação entre as espécies minerais é dada pela capacidade de suas partículas se prenderem a bolhas de ar. Uma vez aderida a uma bolha de gás, a densidade do conjunto partícula-bolha torna-se menor que a do fluido, fazendo com que o conjunto se desloque verticalmente para a superfície, onde fica retido e é separado numa espuma, enquanto que as partículas das demais espécies minerais mantêm inalterada a sua rota (LUZ et al., 2004).

A propriedade de determinadas espécies minerais possuírem maior afinidade com a fase gasosa é designada por hidrofobicidade. Entretanto, este comportamento não é regra no reino mineral, pois praticamente todas as espécies minerais imersas em água tendem a molhar sua superfície, ou seja, têm maior afinidade pela fase líquida, comportamento este designado por hidrofilicidade (LUZ et al., 2004).

O comportamento hidrofílico das espécies minerais pode ser alterado pela introdução de reagentes adequados ao sistema. Qualquer substância mineral pode ser tornada hidrofóbica mediante a adição de substâncias à polpa. Além disso, é possível, estando presentes duas espécies minerais, induzir a hidrofobicidade em apenas uma delas, mantendo a outra hidrofílica, ou seja, é possível induzir uma hidrofobicidade seletiva (BALTAR, 2008).

Com o intuito de aumentar a eficiência e reduzir os custos de flotação, foram desenvolvidos e aperfeiçoados diferentes tipos de máquinas, as quais podem ser divididas em três classes principais: células mecânicas, pneumáticas e de coluna. No entanto, quando o assunto está relacionado à eficiência do processo, vários parâmetros podem contribuir para o aumento ou redução da mesma, como por exemplo, o tamanho e grau de liberação das partículas, massa específica das mesmas, vazão de ar etc.

Este trabalho foi realizado baseando-se na hidrodinâmica de partículas na flotação, com a realização de ensaios em tubo de Hallimond utilizando partículas de apatita, com foco no arraste hidráulico das mesmas.

O arraste hidráulico possui relação direta com a vazão de ar, massa específica e tamanho das partículas, tornando-se imprescindível conhecer o comportamento das mesmas frente a estes parâmetros físicos, o que possibilita quantificar em termos de recuperação, as partículas que foram flotadas e as que sofreram arraste, proporcionando a obtenção do rendimento real do processo de microflotação.

Segundo Drzymala (1994), gases borbulhando através da água em tubos de Hallimond causam arraste de partículas finas. As partículas são arrastadas com uma camada de água viajando atrás das bolhas. Tais partículas estão sujeitas à força da gravidade, causando a sedimentação das mesmas. Então, as partículas 
que apresentam menor velocidade de sedimentação em relação à velocidade da camada de água atrás de bolhas podem ser arrastadas com as mesmas e transferidas ao receptor do tubo de Hallimond. Com base nesse princípio, duas equações para o tamanho máximo de partículas arrastadas (dmáx) no tubo de Hallimond foram derivadas no trabalho realizado por Drzymala (1994). A equação para partículas a qual obedece a lei de Newton de sedimentação é:

$$
d_{\text {máx }}\left(\frac{\rho_{p}-\rho_{l}}{\rho_{l}}\right) \cong L_{H}=\frac{3\left(W_{b}\right)^{2} \zeta}{4 g}
$$

Enquanto que para partículas que se sedimentam de acordo com a lei de Allen, a equação é:

$$
d_{\text {máx }}\left(\frac{\rho_{p}-\rho_{l}}{\rho_{l}}\right)^{0,75} \cong L_{L}=\frac{W_{b}}{113,2}
$$

Onde $\rho_{\mathrm{p}}$ é a massa específica das partículas $(\mathrm{g} / \mathrm{cm} 3), \rho_{\text {I }}$ a massa específica do líquido $(\mathrm{g} / \mathrm{cm} 3), \mathrm{W}_{\mathrm{b}}$ a velocidade vertical de uma bolha dentro da região mais lenta do tubo de Hallimond $(\mathrm{cm} / \mathrm{s})$, $\zeta$ o coeficiente de arraste (número adimensional que depende do número de Reynolds), g a aceleração gravitacional $\left(\mathrm{cm} / \mathrm{s}^{2}\right)$, e LH e LL são constantes.

No trabalho desenvolvido por Drzymala (1994), os testes experimentais realizados em um tubo de Hallimond usando 13 diferentes materiais hidrofílicos confirmaram a aplicabilidade da Eq. (3) para materiais com densidade acima de $2,0 \mathrm{~g} / \mathrm{cm}^{3}$ e a Eq. (4) para aqueles com densidade inferior a $2,0 \mathrm{~g} / \mathrm{cm}^{3}$. As fórmulas experimentais a seguir foram obtidas para partículas com formas regulares:

$$
d_{\text {máx }}\left(\frac{\rho_{p}-\rho_{l}}{\rho_{l}}\right)=L_{H}=0,023 \pm 0,002
$$

para $\rho_{\mathrm{p}} \geq 2,0 \mathrm{~g} / \mathrm{cm} 3 \mathrm{e}$

$$
d_{\text {máx }}\left(\frac{\rho_{p}-\rho_{l}}{\rho_{l}}\right)^{0,75}=L_{L}=0,020 \pm 0,002
$$

para $\rho_{\mathrm{p}}<2,0 \mathrm{~g} / \mathrm{cm} 3$. 
O parâmetro $d_{\text {máx }}$ foi considerado como sendo o tamanho de classificação $D_{50^{\prime}}$ que é utilizado para caracterização de toda a curva de separação referente a um dado mineral, pois cada partícula tendo um tamanho igual ao $D_{50}$ possui a mesma probabilidade de ser arrastada, bem como afundada. Em outras palavras, $D_{50}$ é o tamanho máximo de partícula $\left(\mathrm{d}_{\text {máx }}\right)$ que pode ser arrastada, embora a recuperação de toda a fração de tamanho tendo o diâmetro médio igual ao $D_{50}$ seja somente de $50 \%$. Vale ressaltar que uma vazão de ar constante foi admitida nos ensaios de arraste que compuseram o trabalho realizado por Drzymala (1994).

Em contrapartida, o principal objetivo do presente trabalho consistiu em analisar a influência da vazão de ar no arraste hidráulico em tubo de Hallimond, utilizando partículas de apatita, sem adição de reagentes. Os resultados obtidos foram apresentados na forma de gráfico e a curva constituinte do mesmo foi ajustada através do software Excel.

\section{Metodologia}

De modo a adequar a granulometria da apatita para a realização dos ensaios de arraste, realizou-se a cominuição da mesma em moinho de bolas seguido do peneiramento a úmido, utilizando a série de peneiras Tyler nas malhas $850 \mu \mathrm{m}$ (20\#), $600 \mu \mathrm{m}$ (28\#), $425 \mu \mathrm{m}$ (35\#), $300 \mu \mathrm{m}$ (48\#), $212 \mu \mathrm{m}$ (65\#), $180 \mu \mathrm{m}$ (80\#), $150 \mu \mathrm{m}$ (100\#), $106 \mu \mathrm{m}$ (150\#), $75 \mu \mathrm{m}$ (200\#), $53 \mu \mathrm{m}$ (270\#) e $45 \mu \mathrm{m}$ (325\#). A Figura 1 apresenta a apatita antes da cominuição.

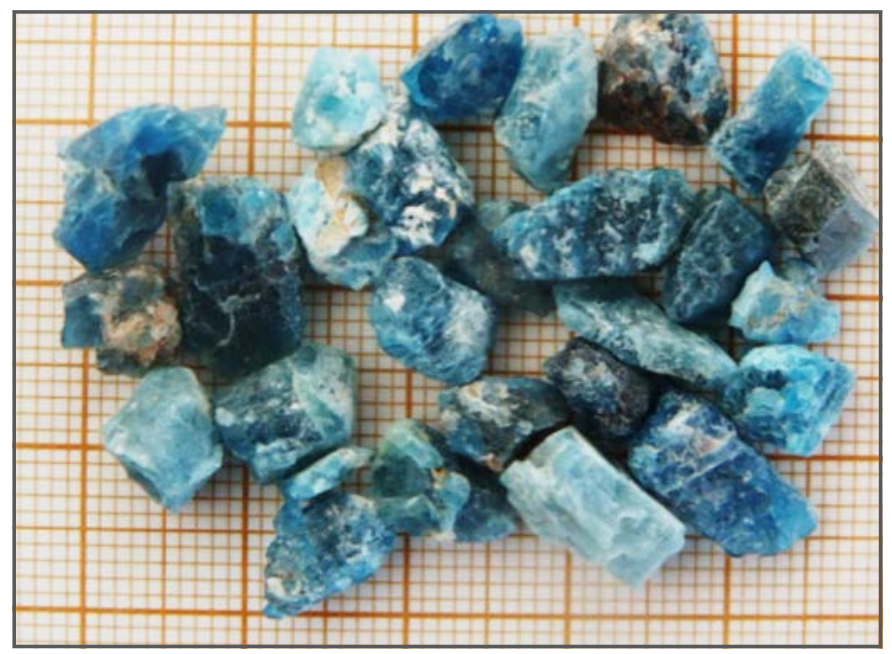

Figura 1. Apatita in natura (antes da cominuição) 
Uma vez finalizado o peneiramento, obteve-se a fração granulométrica utilizada para o desenvolvimento deste trabalho $(-180+150 \mu \mathrm{m})$, conforme a imagem obtida via microscópio marca Stereo Microscópio Laborana, modelo SD500, apresentada na Figura 2. Em seguida, dirigiu-se o material à estufa para secagem, sendo posteriormente armazenado em frasco devidamente identificado.

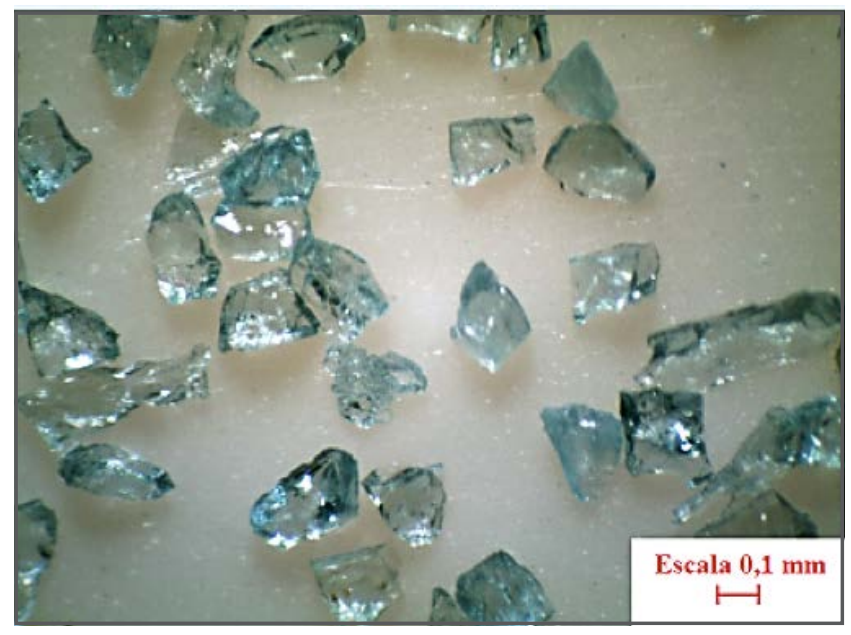

Figura 2. Imagem de microscopia óptica da apatita após cominuição e peneiramento na fração granulométrica - $180+150 \mu \mathrm{m}$

Segundo o DNPM, a massa específica da apatita com alto grau de pureza está entre 3,1 e $3,2 \mathrm{~g} / \mathrm{cm}^{3}$. Portanto, a fim de determinar a massa específica da apatita adquirida para comparar com o exposto em literatura, aplicou-se a técnica de picnometria, utilizando a Eq. (5). Vale ressaltar que o ensaio foi realizado em triplicata.

$$
\rho_{\text {sólido }}=\frac{m_{2}-m_{1}}{\left(m_{4}-m_{1}\right)-\left(m_{3}-m_{2}\right)}
$$

Onde $\mathrm{m}^{1}$ é a massa do picnômetro vazio e seco $(\mathrm{g}) ; \mathrm{m}^{2}$ é a massa do picnômetro com a amostra $(\mathrm{g}) ; \mathrm{m}^{3}$ é a massa do picnômetro com a amostra e água $(\mathrm{g}) ; \mathrm{m}^{4}$ é a massa do picnômetro com água (g).

De modo a conhecer o grau de pureza da apatita, foi realizada a análise química da mesma pela Anglo American Fosfato do Brasil via fluorescência de raios $\mathrm{X}$.

Os ensaios de arraste hidráulico foram realizados em tubo de Hallimond (Figura 3), admitindo massa de 1,0 $\mathrm{g}$ de apatita, conforme procedimento padrão. 


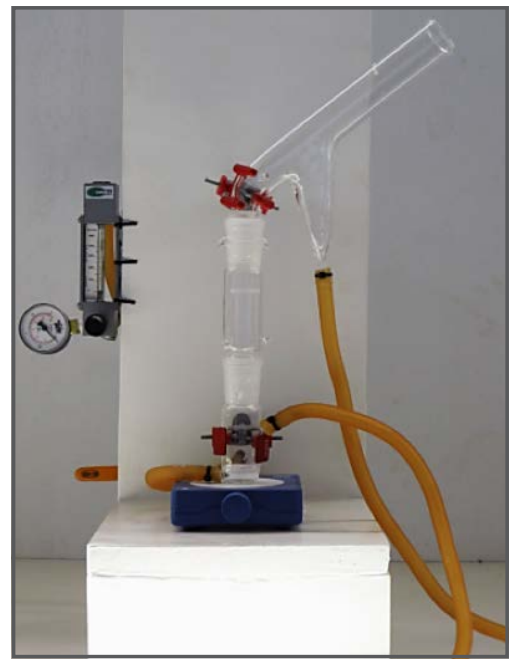

Figura 3. Tubo de Hallimond utilizado na realização dos ensaios de arraste hidráulico

Uma vez realizada a pesagem da quantidade referida de apatita em balança de precisão, prosseguiu-se com a identificação e pesagem dos papéis-filtro, os quais serviram de receptores dos materiais "arrastado" e "afundado", provenientes da descarga do tubo de Hallimond.

As vazões de ar utilizadas nos ensaios foram de $30,35,40$ e $50 \mathrm{~cm} 3 / \mathrm{min}$, medidas através de um rotâmetro marca Dwyer, modelo RMA - ISI - SSV. A faixa granulométrica utilizada nos ensaios de arraste foi de - $180+150 \mu \mathrm{m}(-80+100 \#)$, realizando-se uma correlação entre as vazões de ar e tal granulometria, totalizandose 4 ensaios. A pressão admitida foi de aproximadamente $69 \mathrm{kPa}$ (10 psi) para todos os ensaios, além de uma intensidade de agitação constante para os mesmos.

Os ensaios foram realizados em triplicata, visando à obtenção de resultados representativos. Logo, ao final do trabalho foram realizados 12 ensaios de arraste hidráulico. A Tabela 1 apresenta as condições nas quais ocorreu a realização dos ensaios de arraste.

Tabela 1. Ensaios de arraste hidráulico realizados

\begin{tabular}{cccccc}
\hline $\begin{array}{c}\text { Vazão } \\
\left(\mathrm{cm}^{3} / \mathrm{min}\right)\end{array}$ & $\begin{array}{c}\text { Granulometria } \\
(\mu \mathrm{m})\end{array}$ & $\begin{array}{c}\text { Pressão } \\
(\mathrm{Kpa})\end{array}$ & $\mathrm{pH}$ água & $\begin{array}{c}\text { Tempo de } \\
\text { agitação } \\
(\mathrm{min})\end{array}$ & $\begin{array}{c}\text { Tempo de } \\
\text { aeração } \\
(\mathrm{min})\end{array}$ \\
\hline 30 & $-180+150$ & 69 & 7 & 1 & 1 \\
35 & $-180+150$ & 69 & 7 & 1 & 1 \\
40 & $-180+150$ & 69 & 7 & 1 & 1 \\
50 & $-180+150$ & 69 & 7 & 1 & 1 \\
\hline \multicolumn{5}{c}{ Fonte: autoria própria }
\end{tabular}


A princípio, desmontou-se o tubo de Hallimond, inserindo a barra magnética na parte inferior do mesmo, cujo movimento foi induzido através do agitador magnético, seguido da inserção de uma amostra de $1,0 \mathrm{~g}$ de apatita, montando o tubo novamente. Em seguida, inseriu-se aproximadamente $320 \mathrm{~mL}$ de água destilada com $\mathrm{pH}$ igual a 7 e então, prosseguiu-se com a agitação durante 1 minuto, de modo que todas as partículas ficassem em suspensão. Finalizado o tempo de agitação, ligouse o sistema de pressão e vazão de ar, iniciando a aeração e consequentemente, o ensaio de arraste propriamente dito, o qual também teve uma duração padrão de 1 minuto.

Em seguida, realizou-se a descarga do material contido no tubo de Hallimond em dois béqueres, sendo um destinado a receber o material "afundado" e o outro, o "arrastado", valendo ressaltar que não houve a utilização de reagentes no processo. Realizada a descarga do tubo de Hallimond, iniciou-se o processo de filtragem a vácuo, obtendo-se, portanto, dois produtos: "arrastado" e "afundado".

Concluída a etapa de filtragem, prosseguiu-se com a secagem dos materiais em estufa a uma temperatura de aproximadamente $60^{\circ} \mathrm{C}$ durante nove horas e após a retirada dos mesmos aguardaram-se mais três horas em temperatura ambiente para, posteriormente, realizar a pesagem, conferindo-se assim, a massa de material "arrastado", bem como a massa do "afundado", de modo a verificar tanto a intensidade do arraste quanto a validação do teste, visto que a somatória das massas mencionadas deve ser igual ou bem próxima à massa inicial de amostra utilizada $(1,0 \mathrm{~g})$.

\section{Resultados e discussão}

Na determinação da massa específica da apatita adquirida, os valores obtidos referentes aos ensaios 1, 2 e 3 foram de 3,240, 3,171 e 3,184 g/ $\mathrm{cm}^{\mathrm{w}}$, respectivamente. Assim, calculou-se a média de tais valores, obtendo-se uma massa específica igual a $3,198 \mathrm{~g} / \mathrm{cm} 3 \pm 0,026$, confirmando o exposto na literatura.

A caracterização química realizada pela Anglo American Fosfato do Brasil forneceu os resultados apresentados na Tabela 2.

Tabela 2. Caracterização química da apatita

\begin{tabular}{cccccccc}
\hline Óxidos & $\mathrm{Nb}_{2} \mathrm{O}_{5}$ & $\mathrm{P}_{2} \mathrm{O}_{5}$ & $\mathrm{Fe}_{2} \mathrm{O}_{3}$ & $\mathrm{SiO}_{2}$ & $\mathrm{BaO}$ & $\mathrm{Al}_{2} \mathrm{O}_{3}$ & $\mathrm{CaO}$ \\
\hline Teor $(\%)$ & - & 40,50 & 0,07 & 0,94 & 0,06 & 0,38 & 52,04 \\
\hline
\end{tabular}


De acordo com o banco de dados de minerais da Universidade Estadual Paulista (Unesp), a apatita com alto grau de pureza contém $41,8 \%$ de $\mathrm{P} 2 \mathrm{O} 5$ e $55 \%$ de $\mathrm{CaO}$, valores estes bem próximos aos obtidos na caracterização química.

O gráfico apresentado na Figura 4 apresenta a relação obtida entre o arraste das partículas e a vazão de ar. $O$ ajuste da curva apresentada foi realizado através do software Excel, no qual o melhor ajuste consistiu em uma função polinomial de segundo grau. Através do gráfico, nota-se um aumento no arraste com o aumento da vazão de ar de modo não linear.

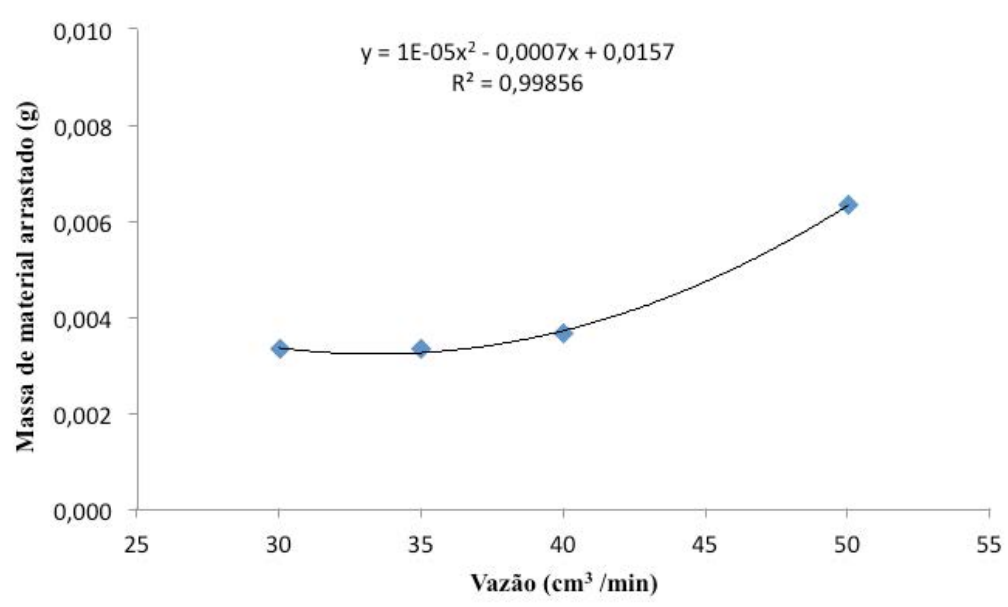

Figura 4. Relação entre o arraste e a vazão de ar

Segundo Drzymala (1994), a Eq. (3) é aplicada para partículas com massa específica superior a $2,0 \mathrm{~g} / \mathrm{cm}^{3}$, que é o caso da apatita, conforme a massa específica obtida via picnometria. Desta forma, aplicando tal equação para a apatita utilizada nos ensaios de arraste, obtém-se um $\mathrm{d}_{\text {máx }}$ de $104,6 \mu \mathrm{m}$, indicando que as partículas que apresentam esta granulometria possuem $50 \%$ de probabilidade de serem afundadas, bem como arrastadas. Percebe-se, portanto, que a fração granulométrica considerada neste trabalho é superior ao $d_{\text {máx }}$ calculado, ou seja, as partículas apresentam uma maior probabilidade de serem afundadas. Além disso, com base no gráfico, pode-se afirmar que a equação em questão é aplicável para vazões mais baixas dentre as consideradas neste trabalho, nas quais não ocorreu arraste significativo, com variação quase linear entre as vazões de 30,35 e $40 \mathrm{~cm}^{3} / \mathrm{min}$.

A Eq. (3) não considera a vazão de ar, uma vez que se manteve a mesma constante nos ensaios de arraste correspondentes ao trabalho realizado por Drzymala (1994), consistindo numa restrição do modelo proposto por este autor, visto que o gráfico 
apresentado na Figura 4 demonstra que o arraste é influenciado pela vazão de ar, tendendo a aumentar com o aumento da mesma.

\section{Conclusões}

A partir do resultado obtido, pode-se afirmar que o arraste hidráulico tende a aumentar com o aumento da vazão de ar, apresentando um comportamento parabólico em relação à variação da mesma para a fração granulométrica analisada. À medida que uma bolha toma uma direção ascendente num meio fluido, as linhas de fluxo as contornam em sentido contrário. Partindo desse princípio, acreditase que ao elevar a vazão de ar, a velocidade de ascensão das bolhas aumenta e, consequentemente, gera uma zona de vácuo mais intensa na região localizada atrás das bolhas, acarretando num maior número de partículas arrastadas.

O arraste hidráulico de partículas é regido por outros parâmetros além da vazão de ar, como a massa específica, tamanho e forma das partículas, dentre outros. Entretanto, a interação entre tais parâmetros é de alta complexidade, exigindo estudos mais avançados. Além disso, ensaios com partículas em outras frações granulométricas devem ser realizados a fim de verificar a influência da granulometria no arraste hidráulico.

Embora escassos, tais estudos contribuem com o fornecimento de informações potenciais quanto à obtenção de maior controle do processo de flotação na indústria, ou seja, possibilita reduzir ou eliminar material contaminante (partículas hidrofílicas) no concentrado. Já no processo de microflotação em tubo de Hallimond, a quantificação do arraste possibilita conhecer o rendimento real do processo de microflotação, visto que é uma técnica a partir da qual se deseja conhecer a máxima eficiência do reagente coletor para determinado mineral. Assim, é evidente que tanto as variáveis físicas quanto as químicas desempenham um papel importante no processo de flotação.

\section{Agradecimentos:}

Os autores agradecem o suporte financeiro das agências CNPq, CAPES, FAPEG e FUNAPE e Universidade Federal de Goiás. 


\section{Influence of the Air Flow in the Hydraulic Entrainment in Hallimond Tube}

Abstract: Flotation is the most used technique in the concentration of low grade ores, which is a very important step for adding value to the product. Based on this, there are several variables that correlate with each other, which are crucial to the success of the flotation process, such as air flow, intensity of shaking, particle size, specific mass and particle shape and degree of release of them. Thenceforth, the hydraulic entrainment of particles deserves highlighting, which is present in the industrial and laboratory flotation process and is influenced by the air flow, specific mass and particle size. Due to the existence of few studies related to this theme, the present work was developed in order to access the influence of the air flow in the hydraulic entrainment in Hallimond tube, using apatite particles. For this, the entrainment tests were executed with one granulometric range and four air flows, without adding reagents. After the testing had been carried out, the results were recorded which were obtained through the weighing of the entrained and sunken particles. Then, it was traced a graph to provide a better view of the behavior of the particles in different air flows in the face of entrainment, showing an increase in the entrainment of the particles with the increase of the air flow.

Keywords: Flotation; Hydraulic entrainment; Air flow.

\section{Referências bibliográficas}

BALTAR, C. A. M. Flotação no Tratamento de Minério. Departamento de Engenharia de Minas UFPE, Recife, 2008.

CHAVES, A. P. Teoria e prática do tratamento de minérios. A flotação no Brasil. $3^{\circ}$ Edição. São Paulo, 2013.

CLIFT, R.; GRACE, J. R.; WEBER, M. E. Bubbles, Drops and Particles. Academic Press. Nova York, 1978.

DRZYMALA, J. Characterization of materials by Hallimond tube flotation. Part 1: maximum size of entrained particles. International Journal of Mineral Processing. Volume 42, p. 139-152, Polônia, 1994. 
LI, R.; HOBERG, H.; SCHNEIDER, F. U. Investigations on the influence of particle size in flotation. In: International Mineral Processing Congress, XVIII. Volume 3, p. 689-697, Sydney, 1993.

LUZ, A. B.; SAMPAIO, J. A.; ALMEIDA, S. L. M. Tratamento de Minérios. $4^{\circ}$ Edição. Rio de Janeiro, 2004.

MACHADO, F. B. Apatita. Disponível em: http://www.rc.unesp.br/museudpm/banco/fosfatos/ apatita.html. Data de acesso: 18 de Novembro de 2014.

PINTO, G. H. V. P. Cinemática de Partículas em Fluidos de Viscosidade Variável com o Tempo e sua Aplicação na Construção de Poços de Petróleo: Avaliação Durante Paradas Operacionais. Dissertação de Mestrado, Universidade Federal do Rio Grande do Norte, 2008.

SAVASSI, O. N.; ALEXANDER, D. J.; FRANZIDIS, J. P.; MANLAPIG, E. V. An empirical model for entrainment in industrial flotation plants. Minerals Engineering. Volume 11, p. 243-256, 1998.

ZHENG, X.; FRANZIDIS, J. P.; JOHNSON, N. W.; MANLAPIG, E. V. Modelling of entrainment in industrial flotation cells: the effect of solids suspension. Minerals Engineering. University of Queensland. Volume 18, Edição 1, p. 51-58, Austrália, 2004. 